\title{
Expandir, repetir, conservar: a sexualidade sob o Eros freudiano
}

\author{
Expanding, repeating, conserving: the sexuality under the Freudian Eros
}

\section{Fábio Moreira Vargas}

Resumo: O presente artigo deseja evidenciar que, ainda que a libido e a sexualidade tenham sido incluídas no conceito de Eros a partir de Além do princípio do prazer, a sexualidade no interior no pensamento freudiana não perdeu seu caráter disruptivo e não deixou de ser considerada como causa de profundas perturbações para a vida psíquica humana. Para tal, serão reconstruídos os argumentos sobre a natureza conservadora das pulsões e se procurará propor a ideia de que os conceitos de expansão, repetição e conservação, intimamente associados à dinâmica pulsional, não podem ser vistos como elementos que teriam retirado à sexualidade sua natureza disruptiva e conflitiva no interior da obra freudiana.

Palavras-chave: Sexualidade e Eros; Além do princípio do prazer; Teoria freudiana das pulsões; Natureza conservadora das pulsões; Eros e Thânatos

Abstract: This work aims to highlight that, although the libido and sexuality have been included in the Eros' concept since the Beyond the Pleasure Principle oeuvre issue, the sexuality, in the core of Freudian thinking, has not lost its disruptive nature, as it has not stopped being considered as source of deep perturbations on human psychological life. To do so, arguments about the conservative nature of impulse will be reconstructed, as well as it will be intended to propose an idea where the concepts of expansion, repetition and conservation, which are tightly associated to drives dynamics, cannot be seen as elements that would have taken the disruptive and conflictive nature from the sexuality, in the Freudian oeuvre.

Keywords: Sexuality and Eros; Beyond the pleasure principle; Freudian drive theory; Conservative nature of the drives; Eros and Thânatos

\section{Sexualidade após Além do princípio do prazer: um conceito harmônico?}

A necessidade fundamental de dar inteligibilidade a noção de conflito, aspecto central da metapsicologia freudiana, resultou, como é sabido, nas duas teorizações pulsionais na obra de Freud. Assim, o primeiro dualismo pulsional opunha por um lado pulsões do Eu, responsáveis pela conversação do organismo, e de outro, pulsões sexuais, estímulos perturbadores que visavam a descarga das tensões e o ganho de prazer. A oposição das exigências de conservação contra as demandas da libido compunha o quadro geral desse momento teórico. O segundo dualismo, então, viria alterar essas peças mantendo, contudo, o conflito em seu lugar: agora, a oposição seria pensada entre Eros,

* Mestrando pelo Instituto de Psicologia da Universidade de São Paulo, São Paulo, SP. E-mail: fabio.vargas@usp.br ORCID: https://orcid.org/0000-0003-4662-9923 
pulsões de vida, contra Thânatos ${ }^{1}$, as pulsões de morte. Esta segunda teoria causou grande discussão (e ainda causa) no interior do campo psicanalítico. Nosso interesse, neste trabalho, é recortar alguns aspectos problemáticos das teorizações freudianas após Além do princípio do prazer.

Em texto dedicado a pensar o estatuto da agressividade e da pulsão de morte em $O$ mal-estar na civilização, Gérard Raulet comenta, sobre a sexualidade no segundo dualismo pulsional de Freud:

Nomeada Eros, a sexualidade - entendida no sentido amplo e incluindo também suas formas sublimadas, não é mais uma força "disruptiva de energia, eminentemente perturbadora", mas uma força de coesão: "a finalidade de Eros é de construir unidades cada vez maiores e de mantê-las assim: é a ligação; a finalidade [ da pulsão de destruição] é, ao contrário, dissolver as conexões e assim destruir coisas. A sexualidade passa para o lado da ligação².

O que se mobiliza nesse excerto é a ideia de que a sexualidade subsumida a Eros estaria sob a égide da conservação das unidades e das tentativas de ligação e agregação. $\mathrm{O}$ raciocínio não é novo e comparece em diversos autores importantes, como no indispensável Vocabulário de Psicanálise, de J. Laplanche e B. Pontalis. Ali, encontraremos:

A pulsão sexual, que Freud, na primeira teoria das pulsões, contrapunha às pulsões de autoconservação, é assimilada no último dualismo pulsional às pulsões de vida, a Eros. Assim como no primeiro dualismo, a pulsão sexual era a força submetida unicamente ao princípio do prazer, dificilmente educável, que funcionava segundo as leis do processo primário e que constantemente ameaçava desde dentro o equilíbrio do aparelho psíquico, agora se converte, com o nome de pulsão de vida, em uma força que tende à ligação, a constituição e manutenção das unidades vitais e, em compensação, sua antagonista, a pulsão de morte, é que funciona segundo o princípio da descarga total ${ }^{3}$.

A sexualidade, incluída em Eros, não se oporia mais necessariamente a organização do Eu, tampouco seria elemento desestabilizador, uma vez que, agora, “[...] é a pulsão de morte que passa a se converter nessa força primária, demoníaca, e propriamente pulsional,

\footnotetext{
${ }^{1}$ Freud não se serviu desse termo para designar as pulsões de morte, mas a palavra consagrou-se na literatura especializada e não nos parece um equívoco mantê-la nesse trabalho. Nossa discussão não enveredará por questões terminológicas dessa natureza.

${ }^{2}$ RAULET, As duas faces da morte. Sobre o estatuto da agressividade e da pulsão de morte em O mal-estar na civilização, p. 76.

${ }^{3}$ LAPLANCHE; PONTALIS, Diccionario de psicoanálisis, p. 333, tradução nossa.
} 
enquanto que a sexualidade, paradoxalmente, passa para o lado da ligação" ${ }^{4}$. Esta orientação, pensar a sexualidade sob a égide da ligação e da conservação das unidades via Eros, é de fato um raciocínio presente em Freud. São inequívocas as passagens em que tal articulação se estabelece. Mas daí concluir que a sexualidade teria perdido seu estatuto disruptivo e perturbador nos parece um passo mais complicado e cheio de armadilhas do que se poderia supor rapidamente.

E aqui não desejamos tangenciar apenas pela questão da dessexualização presente em algumas tendências da psicanálise pós-freudiana ${ }^{5}$. Tendência tão surpreendente nos rumos de algumas ideias que faz com que o tema mesmo da sexualidade possa figurar de modo quase obtuso, sem muita ênfase em algumas psicanálises ${ }^{6}$. Situação que faz com que André Green, provocativamente, possa enunciar: tem a sexualidade alguma coisa a ver com a psicanálise? ${ }^{7}$ Essa provocação associa-se, certamente, ao nosso tema, mas desejamos aqui adentrar uma questão mais específica no interior das reflexões sobre a noção de sexualidade na obra de Freud que, concomitante a dessexualização às vezes assistida, também não cessa de estar presente nas interpretação de Freud.

Nosso ponto, portanto, será: teria a introdução da noção de Eros removido da sexualidade suas formas disruptivas e perturbadoras que formam uma de suas tessituras mais próprias pelo menos desde os Três ensaios sobre a teoria da sexualidade? De que modo a noção mítico-filosófica de Eros se arranja no interior nas conceituações sobre a sexualidade humana para que se tornasse inevitável que uma das mais profundas descobertas freudianas (precisamente a sexualidade como lócus da disruptividade) passe, surpreendentemente, para "o lado da ligação”? Se essa orientação teórica se afigura, então não há outra alternativa senão concluir que Além do princípio do prazer é muito mais do que uma obra profundamente radical, embaraçadora e um dos mais fascinantes textos de Freud, mas seria também, simultâneo à reorganização da teoria pulsional, a desmontagem gradativa do próprio estatuto da noção de sexualidade, tal como intensamente elaborada nos anos subsequentes a 1920.

\footnotetext{
${ }^{4}$ LAPLANCHE; PONTALIS, Diccionario de psicoanálisis, p. 344, tradução nossa.

${ }^{5}$ Seguimos, a este respeito, as teses de André Green (1995), para quem as teorias de relações de objeto, desenvolvidas, por um lado por M. Klein e, por outro, por R. Fairbairn deveriam ser pensadas como psicanálises que dessexualizariam a teoria psicanalítica. Este ponto é complexo, polêmico e controverso, mas não é nosso interesse discutir essa questão nesse trabalho.

${ }^{6}$ É sabido, inclusive, que as orientações que se puseram a dessexualizar a teoria freudiana ocorreram no interior mesmo do círculo psicanalítico de Freud. Bastaria lembrarmos a empolgação com a qual Jung, acerca de suas conferências na América no Norte, mostrava-se satisfeito por ter diminuído as virulentas resistências à psicanálise precisamente por tê-la apresentado sem dar tanto peso às questões sexuais. Acompanhando algumas dessas discussões e alguns personagens importantes desse processo, recomenda-se o texto: HOFFMANN, B. A Por uma psicanálise com sexualidade. In: SIG - Revista de psicanálise, n.1, vol. 2, p. 37 $50,2013$.
}

${ }^{7}$ GREEN, Sexualidade tem algo a ver com a psicanálise?, p. 217. 
E aqui indicamos a conclusão do presente trabalho: não pensamos ser essa a melhor maneira de nos aproximarmos do referido texto, na medida em que a noção de Eros, a despeito das complicações, dilemas e questões que nos apresenta no interior do campo teórico psicanalítico, não nos autoriza a bloquear o caráter de negatividade inerente à experiência sexual, isto é, negatividade aqui entendida como elemento intrinsecamente perturbador da vida humana, disruptivo, aspecto sempre conflitivo no interior de nossa experiência psíquico-orgânica. Trata-se, destarte, de evidenciar nossas razões para sair em defesa desse ponto. Interna a nossa questão central e concomitante a ela, propomos igualmente uma organização conceitual de algumas complexas articulações que Freud excuta em Além do princípio do prazer e que se desdobram em escritos posteriores.

\section{As pulsões e suas faces}

Para que nossa questão ganhe inteligibilidade será preciso enfrentar algumas difíceis articulações no interior das teorizações freudianas, precisaremos enveredar pelas complexidades da ideia de que as pulsões, de modo geral, são conservadoras e ao mesmo tempo que Eros possui uma natureza expansionistas, agregadora. Assumamos, inicialmente, a ideia de que alguma coisa se altera na concepção de sexualidade quando esta passa a estar subsumida ao conceito de Eros. E, de fato, esse passo é, como sabido, explícito nos textos de Freud. Em $O$ Eu e o id e em Novas conferências introdutórias à psicanálise, respectivamente, lê-se

Acerca dos instintos ${ }^{8}$ desenvolvi recentemente (em Além do princípio do prazer) uma concepção que aqui manterei e tomarei como base para as discussões que seguem. De acordo com ela, há que distinguir duas espécies de instintos, das quais uma, os instintos sexuais ou Eros, é de longe a mais visível e mais acessível ao conhecimento?.

A ideia de uma oposição no interior da vida instintual, logo achou uma outra, mais aguda expressão. Mas não lhes exporei como surgiu essa novidade da teoria dos instintos; também ela se baseia essencialmente em

\footnotetext{
${ }^{8}$ Como baseamo-nos, principalmente, na tradução das obras de Freud para o português da editora Companhia das Letras, sob direção de tradução de Paulo César de Souza, manteremos nos excertos destacados a palavra instinto para verter "trieb”, assim como consta nesta tradução. Mas nossa opção ao longo do texto será por verter o substantivo alemão por pulsão. Assim, ainda que possa parecer estilisticamente menos rigoroso, não alteraremos a tradução que utilizamos, destacando, aqui, que, no presente trabalho, os termos “instinto” e “pulsão” serão tomados como sinônimos. Logo, não nos interessará na presente discussão a longa questão sobre as traduções desse termo fundamental. Igualmente, acerca das discrepâncias entre os termos Id ou Isso, tomamos os termos por sinônimos e nos abstemos de entrar nessa discussão no presente trabalho.

${ }^{9}$ FREUD, $O$ eu e $o$ id, p. 50.
} 
considerações biológicas; eu a apresentarei aqui como produtos acabados. Nós supomos que haja dois tipos de instintos essencialmente diversos, os sexuais no sentido mais amplo, Eros, se preferirem o termo, e os agressivos, cuja meta é a destruição ${ }^{10}$.

Não há dúvidas, a julgar por essas duas passagens, de que, de fato, sexualidade e Eros coincidem e que o segundo dualismo pulsional faz com que esse último subsuma a sexualidade a partir de 1920. Mas, infelizmente, as coisas não são tão simples quando se trata de Freud, e esta questão precisa ser investigada sob outras perspectivas se se deseja penetrar mais a fundo nesse tema sinuoso. Assumida a ideia de que houve mudanças acerca da sexualidade no segundo dualismo pulsional, é preciso ainda destacar alguns elementos acerca da teoria pulsional que julgamos ser um dos pontos mais espinhosos da teorização freudiana.

Vejamos a seguinte passagem de O Eu e o Id: “Ambos os instintos comportam-se de maneira conservadora no sentido mais estrito, ao se empenhar em reestabelecer um estado que foi perturbado pelo surgimento da vida" ${ }^{11}$. Freud está se movendo, como ele mesmo anuncia, fielmente às teses de 1920, pois encontraremos lá a mesma posição assumida acerca da vida pulsional:

Um instinto seria um impulso presente em todo organismo vivo, tendente à restauração de um estado anterior, que esse ser vivo teve de abandonar por influência de perturbadoras forças externas, uma espécie de elasticidade orgânica ou, se quiserem, a expressão da inércia da vida orgânica. Tal concepção do instinto soa estranha, pois já nos habituamos a ver nele o fator que impele à mudança e ao desenvolvimento e devemos agora reconhecer ali a expressão da natureza conservadora do vivente ${ }^{12}$.

Não há vacilações por parte de Freud: as pulsões são conservadoras, no sentido estrito da palavra e parece, ao que tudo indica, que residiria aí uma quinta característica acerca das pulsões que se acresceria às clássicas já estabelecidas desde As pulsões e seus destinos, em $1915^{13}$. Mas sem que essa consideração seja negada, encontraremos igualmente afirmada a posição de que há uma tendência expansionista associada a Eros, que, ademais, é uma das duas pulsões elementares e, portanto, seria igualmente conservadora. Assim, à diferença da pulsão de morte, Eros "busca o objetivo de, agregando cada vez mais amplamente a substância viva dispersa em partículas, torna mais complexa a

\footnotetext{
${ }^{10}$ FREUD, Novas conferências introdutórias à psicanálise, p. 252.

${ }^{11}$ FREUD, $O$ eu e $o$ id, p. 50.

${ }^{12}$ FREUD Além do princípio do prazer, p. 2002

${ }^{13}$ Que são: fonte (Quelle), meta ou objetivo (Ziel), sua dimensão impulsiva, motora, essencialmente energética (Drang) e seu objeto, aquilo pelo qual uma pulsão poderá atingir sua meta (objekt)
} 
vida, nisso conservando-a, naturalmente" ${ }^{14}$. Assim, o objetivo de Eros seria o de sempre produzir “[...] unidades cada vez maiores"15.

Temos as peças dispostas para nosso itinerário inicial: ao que tudo parece indicar, as pulsões são descritas como estritamente conservadoras, colocando em xeque a ideia até então assumida de que seriam a causa do movimento, da transformação, dos processos de desenvolvimento e, ao mesmo tempo, no que concerne a Eros, é preciso supor uma natureza expansiva, agregadora, objetivando criar uniões cada vez maiores e, ligando, torna-se a pulsão do movimento, da união e dos processos de agregação. Há que se concluir, então, com Laplanche, Pontalis e Raulet - uma vez que a libido fora englobada na tessitura teórica própria da noção de Eros, então a sexualidade passou para o campo da ligação e nos parece possível defender, deveras, que seu caráter disruptivo e profundamente perturbador ficara para trás na obra de Freud. Todavia, o que assistimos é muito mais a montagem de um emaranhado de questões do que a possiblidade de conclusões definitivas e simples. Em primeiro lugar, porque nem todo texto de Freud parece estar disposto a identificar tão facialmente libido e Eros (como veremos em breve). E em segundo lugar, a ideia da conservação aqui destacada não se encerra em si mesma: afinal, conservar o quê?

\section{Conservação e expansão: Eros versus Thânatos}

Reflitamos brevemente, então, sobre essa ideia da conservação pulsional. À primeira vista, poderia ser suposto, pela letra do texto de Freud que citamos, que se teria apresentado um conjunto de articulações simples evidenciando que toda pulsão, e esta universalidade é afirmada no texto de 1920, seria estritamente conservadora. Mas sabemos que a argumentação de Freud não se esgota nessa constatação derivada de sua polêmica aproximação com as teses biológicas amplamente estruturantes de Além do princípio do prazer ${ }^{16}$; ao contrário, há uma longa e densa caminhada teórica por parte de Freud para que essa ideia possa desdobrar-se nas mais impactantes teses do texto: a natureza mesma da pulsão de morte e a explicitação dos fenômenos de repetição. Mas sigamos por parte porque há uma conhecida construção labiríntica no texto freudiano e não podemos perder algumas peças de sua argumentação sob risco de não deslindarmos nossa questão central.

\footnotetext{
${ }^{14}$ FREUD, $O$ eu e $o$ id, p. 50.

${ }^{15}$ FREUD, O mal-estar na civilização, p. 86.

${ }^{16}$ Orientação biológica que não cessou de escandalizar alguns autores importantes, como o próprio J. Laplanche, que chegou mesmo a dizer tratar-se de um “desvio biologizante" por parte de Freud. Cf. LAPLANCHE, J. Freud e a sexualidade: o desvio biologizante. Rio de Janeiro: Jorge Zahar, 1997.
} 
Comecemos por separar elementos importantes. Quando nos aproximamos da ideia de conservação é necessário não tomar as duas pulsões por homogêneas. Esse passo é fundamental e nem sempre é assistido. Assim, à pergunta "o que se conserva?” é preciso contrapor outra: “em relação a Eros ou a pulsão de morte?”. Deveras, estamos convencidos de que, sem essa prévia atenção, as coisas embaralhamse de modo complicado. Assumamos, então, esta distinção e dirijamo-nos para Thânatos.

Sabemos que pela criatividade e competência de algumas interessantes leituras acerca das teses de Freud contidas em Além do princípio do prazer, muitas perspectivas se abriram a partir de suas especulações metapsicológicas sobre repetição, conservação e expansão. É o caso de Deleuze ${ }^{17}$, e ficaremos com apenas um exemplo, para quem as posições de Freud seriam profundamente disruptivas em relação à tradição metafísica precisamente pela ideia de que a repetição freudiana seria um algo mais originário do que as categorias da ontologia clássica na medida em que, configurada como um pulsar ininterrupto, não buscaria repetir este ou aquele estado prévio, esta ou aquela situação, mas um puro ato repetidor em si mesmo, sem fim ou início. A despeito da sempre interessante e interessada leitura de um filósofo sobre outro grande pensador, é importante não tomar Freud pelo que, de fato, ele não é. Pois nesse automatismo da repetição, presente de forma demoníaca e que se torna tema de grande parte do texto freudiano, há algo que não pode ser posto em dúvida: a repetição em Freud não é um puro pulsar sem destino, mas ela almeja realmente, atingir um estado anterior.

Pode parecer ao leitor que fugimos, subitamente, de nossa linha de investigação, mas estamos inteiramente nela, pois a pergunta pela conservação nos faz retomar precisamente essa ideia ao evidenciar que quando aplicamos a ideia de conservação à pulsão de morte trata-se, precisamente, de lembrarmos que o que ela deseja conservar é exatamente um estado perdido e que, desde então, luta para reencontrá-lo: nesse sentido, se a pulsão é um impulso, não podemos perder de vista ao que ele impele, e descobrimos que, no caso das pulsões de morte, trata-as de "um velho estado inicial, que o vivente abandonou certa vez e ao qual ele se esforça por voltar através de todos os rodeios do seu desenvolvimento" ${ }^{18}$. Portanto, no caso de Thânatos, o que se deseja conservar é o estado inorgânico anterior ao surgimento da vida, deseja-se manter o organismo livre de excitações a tal ponto que se possa retornar à quietude da morte ${ }^{19}$.

\footnotetext{
${ }^{17}$ Cf. DELEUZE, G. Diferença e repetição. São Paulo, Editora: Paz \& Terra, 2018.

${ }^{18}$ FREUD, Além do princípio do prazer, p. 204.

${ }^{19}$ No texto que compõe as Novas conferências introdutórias à psicanálise, de 1933, no momento de discorrer sobre o segundo dualismo pulsional, Freud enfatiza principalmente a dimensão da agressividade e da violência que deriva das considerações da pulsão de morte como retorno ao inorgânico. Mas não há, nesse ponto, contradição alguma: por intermédio de Eros, e pela possiblidade da motilidade do corpo orgânico, a
} 
Um novo dualismo pulsional desenhou-se, como é sabido, para reorganizar os frutos dessa posição de Freud: há uma pulsão que, de morte, deseja retornar ao estado anterior à vida e outra, oposta a ela, que desejaria, ligando, unindo, agregando, atingir a meta contrária. Assim, as questões concernentes às pulsões de morte pareceriam se ordenar de modo muito satisfatório, na medida em que a conservação é compreendida porque não deseja expandir, aumentar, mas conservar o estado perdido, lutar para impedir novas tensões, no limite, destruir a circulação energética do próprio organismo, eliminando as novas tensões que constantemente lhe bombardeiam:

Se é verdadeiro que - em tempos imemoriais e de modo inconcebível - a vida se originou da matéria inanimada, então, segundo nossa premissa, deve ter surgido naquele momento um instinto que procura abolir a vida, restaurar o estado inorgânico. Se reconhecemos nesse instinto a autodestruição da nossa hipótese, podemos vê-la como expressão de um instinto de morte que não pode estar ausente em nenhum processo vital. Agora os instintos em que acreditamos se dividem nos dois grupos que são: o dos eróticos, que buscam aglomerar substância viva em unidades cada vez maiores, e dos instintos de morte, que contrariam esse esforço e reconduzem o elemento vivo ao estado inorgânico ${ }^{20}$.

Assim, contrário a tendência mortífera, eis as pulsões eróticas, Eros, que querem criar "unidades cada vez maiores”, querem agregar, ligar, unir. Acerca disso, e quanto a Eros? Retomemos nossa questão: esta estrutura de repetição e conservação pode ser compreendida da mesma forma quando se trata das pulsões de vida? De fato, ao construir esse modelo de conservação, Freud procura explicitamente enquadrá-lo às pulsões de vida. Mas, ao que tudo indica, isso faz surgir enormes problemas.

A dificuldade das questões colocadas quando se trata de Eros não escapou ao próprio Freud. Em nota de $O$ mal-estar na civilização, no momento que apresenta um pouco do percurso até o segundo dualismo pulsional, pontua: "A oposição que aí surge, entre a incansável tendência expansionista de Eros e a natureza em geral conservadora dos instintos, é algo que chama a atenção e que pode vir a ser ponto de partida para outras indagações” ${ }^{21}$. A despeito de tratar-se de uma nota de rodapé, a centralidade desse excerto é nuclear para nós: Freud mesmo compreende uma “oposição” entre as duas ordens de processos que estamos aqui investigando, de fato, há um evidente contraste entre a ideia de expansão, associada a Eros, e de

tendência à própria morte é expulsa do corpo e aparecerá como agressão contra os objetos. A legitimidade ou não desse passo de Freud não será, contudo, tema do presente trabalho.

${ }^{20}$ FREUD, Novas conferências introdutórias à psicanálise, p. 257-8.

${ }^{21}$ FREUD, O mal-estar na civilização, p. 86. 
conservação, assumida como a "natureza em geral” das pulsões. O curioso é que Freud indica ser esse tema para futuras investigações, mas, ao que queremos mostrar agora, já há uma construção na letra do próprio Além do princípio do prazer que faz com que essa suposta oposição consiga ser mais bem organizada, senão, resolvida. Isso está inteiramente dentro da forma com a qual lidamos com a questão ao assumir que a ideia de conservação significa, de fato, coisas distintas quando aplicada às duas pulsões.

Retomamos a pergunta para que não nos percamos: a pulsão é conservadora, mas, no caso de Eros, conservar o quê?

\section{Em busca da unidade perdida}

No momento em que suas especulações o conduzem exatamente a este impasse, Freud recorre (o que não é nada surpreendente em se tratando de sua obra) à filosofia, especificamente à platônica (ao menos a uma das obras do filósofo ateniense) para evidenciar que, já há muito, é conhecida certa derivação de uma pulsão da necessidade de restaurar um estado anterior. Freud, nesse caso, está interessado na pulsão sexual e, servir-se-á da teoria apresentada por Aristófanes, personagem do Banquete.

Destaquemos claramente, e de saída, porque esse ponto é fundamental: não se trata, na estrutura argumentativa do texto freudiano, de um recurso exterior à lógica teórica que se está construindo acerca das pulsões, ao contrário, o argumento filosófico que Freud faz figurar é estritamente necessário se se deseja dar inteligibilidade às suas posiçôes acerca da ideia de conservação e aplicá-la a Eros. Passemos a palavra ao próprio texto freudiano: “Devemos seguir a deia do filósofopoeta e arriscar a suposição de que a substância viva, ao ser animada, foi desmembrada em pequenas partículas que desde então buscam reunir-se de novo mediante as pulsões sexuais?”22.

Assim, Freud está em condições, apesar de todas as vacilações que ele mesmo anuncia, de aproximar a ideia de conservação com as especulações acerca das pulsões sexuais: elas tenderiam, igualmente, a "restaurar um estado anterior" 23 mas, diferentemente das pulsões de morte, o objetivo não é retornar ao inorgânico, mas a uma suposta unidade que teria sido perdida no momento do surgimento da vida em que a matéria orgânica se teria dividido. Assim, a especulação que retoma Platão para explicitação da tese, poderia ser organizada da seguinte maneira: no momento mesmo em que a substância orgânica nasce da inorgânica, em que a vida surge da matéria

\footnotetext{
${ }^{22}$ FREUD, Além do princípio do prazer, p. 232.

${ }^{23}$ FREUD, Além do princípio do prazer, p. 230.
} 
inanimada, seria preciso supor que ocorrera uma divisão da unidade originária e, nesse "inconcebível momento", dois processos teriam surgido concomitantemente. As duas pulsões serem tomadas como conservadoras se torna, desse ponto de vista, algo inteligível, pois a pulsão de morte desejaria retornar ao estado anterior, isto é, a forma inorgânica, enquanto as pulsões sexuais tenderiam, unindo e ligando unidades cada vez maiores, reencontrar a unidade perdida, restaurando, igualmente, um estado anterior.

Assim, a conservação se torna compreensível no interior da argumentação sobre a ligação e não é necessariamente oposta ao aspecto expansionista de Eros. É preciso admitir que ainda que ambígua, vacilante e com alguns problemas, é uma forma de organizar as coisas e é um argumento, ademais, do próprio Freud. O que parece se desenhar, então, é que há uma articulação bastante sofisticada na letra freudiana em que os conceitos de conservação, repetição e expansão estão unidos às duas problemáticas pulsionais ainda que constituam processos com especificidades particulares. Eros introduz tensões, coloca movimentos, liga, eleva os níveis energéticos do organismo e do aparelho psíquico para, unindo, articulando as partes isoladas, reencontrar a unidade que fora perdida e, assim, conservá-la. Assistimos, num jogo de idas e vindas, de adiantamentos e regressões argumentativos, um raciocínio que faz com que expansão não seja necessariamente oposta à conservação e que a vida e seus fenômenos de movimento, de energização, de transformações, possam ser expansivos ainda que desejem conservar. Mesmo o soberano princípio do prazer, explicitamente subordinado à morte ${ }^{24}$ ao no final de Além do princípio do

\footnotetext{
${ }^{24} \mathrm{Na}$ introdução do texto O problema econômico do masoquismo, 1924, Freud proporá uma reorganização terminológica acerca das relações entre os princípios de regulação do aparelho psíquico e as duas ordens de pulsões. De fato, é possível compreender essa introdução como uma organização terminológica que auxilia na resolução de algumas ambiguidades deixadas pelo texto de 1920. O problema residia, sobretudo, na relação princípio de prazer e pulsão de morte que, em Além do princípio do prazer, apareciam intimamente associados, a ponto de Freud concluir (em franca contradição ao que havia afirmado na mesma obra) que o princípio do prazer parece estaria à serviço das pulsões de morte. A organização elucidada no texto sobre o masoquismo arranja as peças da seguinte forma: há um princípio que faz com que o aparelho psíquico escoe toda energia de seu interior e que Freud nomeia princípio de Nirvana (termo e Barbara Low) e que fora apressadamente identificado ao princípio do prazer. Por essa lógica, é evidente que a busca por prazer e a evitação do desprazer estão diretamente ligados a diminuição de energia no aparelho e, como tal, tendem a morte, logo, às pulsões de morte. Freud corrige essa questão separando os dois princípios e explicando que o princípio de Nirvana pertence às pulsões de morte, mas ele sofre uma modificação que o faz tornar-se princípio do prazer (e que devemos, portanto, compreender como coisas distintas, sendo este último não o escoamento total e completo de toda energia, mas de certa forma, recuperando os argumentos sobre a ideia de constância, o aparelho deve aprender a lidar com uma quantidade mínima de energia dentro de si sem a qual o próprio funcionamento psicológico não seria possível). A modificação que faz essa transformação não pode advir de outra coisa senão de Eros, assim, a libido teria conquistado, junto às pulsões de morte, sua participação dos processos de regulamentação da vida. Assim, conclui Freud que o princípio de Nirvana
} 
prazer $^{25}$, na medida em que regula os processos econômicos no aparelho psíquico e é obrigado a conviver com tensões constantes oriundas de Erros e mobilizar toda sorte de recursos para lidar com os aportes energéticos, não parece impedir que Eros, perturbando a lógica mortífera de Thânatos, deseje igualmente conservar. Nesse ponto de vista, sendo o princípio do prazer uma “formação de compromisso", está nele suposto as duas tendências: Eros impede que a energia interna ao organismo seja nula, mas nem por isso, suas tensões e intensidades não estão lutando pela conservação.

Mas, como já afirmamos anteriormente, em se tratando de Freud e acima de tudo do texto de 1920, as coisas não são simples como se poderia supor. Pois ainda que o argumento filosófico, de fato, organize algumas peças muito complicadas de serem encaixadas no todo, há diversas passagens em que Freud não só parece recuar nas suas teses anteriores, como francamente nos devolve às desorientações, a ponto de, como vimos na nota de $O$ mal-estar na civilização, o tema ainda aguarda estudos futuros. Estudos que, ademais, não foram oferecidos por Freud a ponto de, nos assuntos pulsionais, não podermos nos decidir por alguma orientação sem que sempre restem sérias dúvidas.

As hesitações já se iniciam no próprio Além do princípio do prazer. No mesmo movimento em que anuncia a teoria presente no Banquete e começa a desdobrar a tese exposta por Aristófanes, Freud pontua:

Acho que nesse ponto devemos parar. Mas não sem acrescentarmos algumas palavras de reflexão crítica. Talvez me perguntem se e até onde estou convencido das hipóteses aqui apresentadas. A resposta seria que eu próprio não estou convencido nem peço que outros nelas acreditem. Ou, mais precisamente: não sei até onde ceio nelas ${ }^{26}$

serviria as pulsões de morte, o princípio do prazer é reivindicação da libido e seu aumento inevitável de energia no aparelho e, o princípio de realidade está atrelado à relação do sujeito com o mundo externo. Se por um lado essa organização das ideias é importante por esclarecer algumas ambiguidades presentes desde 1920 em relação aos princípios e as pulsões, por outro lado alguns problemas permanecem presentes e a relação prazer-desprazer e atividade pulsional não ganha tanta clareza como se poderia esperar. Esclarecemos esses pontos porque eles estão presentes na complexidade do tema que aqui abordamos, mas não enveredaremos precisamente por eles para a construção de nossos argumentos nesse trabalho. O que é importante destacar é a ideia de que a instauração do princípio do prazer é um processo em que se torna presente a luta entre as duas pulsões e se há uma constante vacilação por parte de Freud acerca da ideia de que é preciso manter um nível mínimo de energia ou se o aparelho psíquico deseja livrar-se de toda energia, talvez as duas coisas correspondam precisamente a esse imbricamento assumido em 1924 entre Eros e Thânatos e a instauração dos princípios de regulação da vida mental.

${ }^{25}$ FREUD, Além do princípio do prazer, p. 238.

${ }^{26}$ FREUD, Além do princípio do prazer, p. 232. 
Assim, estamos expostos a uma complicada situação: há argumentos importantes para dar inteligibilidade a teses complexas, difíceis de serem articuladas sem dubiedades, mesmo conflitantes, e ao mesmo tempo, há hesitações explícitas por parte de Freud no que concerne a validade desses argumentos. As vacilações, quanto a teoria da unidade primordial, também aparecerão em um de seus últimos textos e, como é reconhecido, uma das mais densas e bem articuladas produções de Freud, Compêndio de psicanálise. A respeito do tema que abordamos, encontraremos ali uma interessante passagem:

Se supormos que o vivo surgiu depois do inanimado e que é dele decorrente, então a pulsão de morte está de acordo com a mencionada fórmula, segundo a qual uma pulsão aspira pelo retorno a um estado anterior. Em relação a Eros (ou pulsão de amor) não podemos fazer uso dessa fórmula. Isso pressuporia que a substância viva foi antes uma unidade posteriormente destruída e que agora aspiraria a reunificação ${ }^{27}$.

Aqui, não parece então que a natureza conservadora de Eros fora abandonada? Destaquemos mais uma vez o imbróglio: em 1920, na embaraçosa Além do princípio do prazer, lançam-se teses acerca da possiblidade de compreender a natureza conservadora das pulsões e isso é aplicado a todas as pulsões. Para dar conta dos problemas que isso suscita, é suposta a teoria da unidade primordial que se teria rompido com o surgimento da vida e, nesse momento, haveria uma pulsão que deseja reencontrar esta suposta unidade. Em 1923, no $E u$ e no id, Freud move-se rigorosamente no mesmo quadro e, sem citar a teoria platônica, avança com a tese de que ambas as pulsões se comportam de forma conservadora, destacando inclusive que "a questão da origem da vida permaneceria cosmológica, a da finalidade e propósito da vida seria respondida de forma dualista" ${ }^{28}$, isto é, o compromisso entre vida e morte. Em o Mal-estar na civilização, 1930, veremos, novamente, um recuo da tese evidenciando as complicações dessa identidade entre caráter expansivo de Eros e a natureza conservadora das pulsões. Em 1933, nas Novas conferências introdutórias à psicanálise, desenha-se mais uma vez a ideia de que a pulsão deseja um retorno a um estado anterior mas, no que tange ao nosso tema, Freud anuncia "Se o caráter conservador é próprio de todos os instintos sem exceção, se também os instintos eróticos querem restabelecer um estado anterior quando tendem à síntese do que é vivo em unidades maiores - também esta questão taremos que deixar sem resposta" 29. E, finalmente, no Compêndio de psicanálise, de 1938, mais uma vez Freud se mostra vacilante e, o que é muito interessante, a despeito de precisar, consonante a nossa

\footnotetext{
${ }^{27}$ FREUD, Compêndio de psicanálise, p. 25.

${ }^{28}$ FREUD, $O$ eu $e$ id, p. 51.

${ }^{29}$ FREUD, Novas conferências introdutórias à psicanálise, p. 258.
} 
argumentação, que para postular a ideia de conservação a Eros seria preciso supor o argumento da unidade perdida (articulação que ele mesmo fizera), ele não nega explicitamente que essa especulação fora descartada. Apesar de anunciar que a fórmula do "estado anterior" não parece se enquadrar completamente a Eros, a passagem termina relembrando a tese platônica, mas não avança nenhuma linha a mais além do ponto em que já nos encontrávamos pelo menos desde 1920: na hesitação e na complexidade de compreender satisfatoriamente esses argumentos.

Assim, é preciso admitir o que parece ser o mais razoável: Freud, nessa matéria específica, não nos legou senão indicações, orientações de leitura que se afirmam, se reafirmam, depois parecem ser gradativamente deslocadas, perdem sua ênfase argumentativa para, mais uma vez, serem retomadas. E precisamente pelo fato de que Freud nos deixa com ferramentas teóricas e poucas trilhas indubitavelmente certas que Além do princípio do prazer segue sendo, após cem anos de sua publicação, uma das mais inquietantes obras da psicanálise e uma das mais férteis e difíceis searas nas teorizações freudianas.

Retornemos, contudo, sem fugirmos desses inevitáveis deslocamentos que o próprio texto de Freud nos oferece, para nossos interesses principais: mantida a hipótese de trabalho que aqui reconstruímos, de fato é possível, sem mais, associar a sexualidade aos fenômenos da ligação, da unidade, da expansão e, com isso, retirá-la do campo da disruptividade? Veremos que toda nossa discussão precedente nos auxiliará nessa importante questão.

\section{Pulsão e sexualidade: trabalho à psique.}

Retomemos, mesmo que em linhas gerais, a forma como a sexualidade associada a uma atividade pulsional fora caracterizada no primeiro dualismo pulsional, aquele construído, sobretudo, nos artigos de metapsicologia ${ }^{30}$. O conceito de pulsão, a despeito da centralidade com que é tratada por Freud, não se constitui numa categoria de fácil determinação, muito pelo contrário, há ambiguidades nas definições apresentadas desde o início. Quando nos debruçamos, por exemplo, sobre as tentativas de definição da pulsão no ensaio As pulões e seus destinos, encontraremos a seguinte definição: ela é pensada como "representante psíquico dos estímulos oriundos do interior do corpo e que atingem a alma, como uma medida de trabalho imposto à psique por sua ligação com o corpo"31. Aqui, não parece haver dúvida da

\footnotetext{
${ }^{30}$ Dizemos nos artigos de metapsicologia, pois as teses que são construídas nesses textos serão utilizadas por Freud, de modo bastante fiel, nas edições de os Três ensaios sobre a teoria da sexualidade que, portanto, incorporará essas construções posteriores.

${ }^{31}$ FREUD, Os instintos e seus destinos, p. 57.
} 
íntima articulação estabelecida entre pulsão e representação psíquica, isto é, nesse texto não parece haver nenhuma diferença entre ambas. As excitações corporais não seriam as pulsões propriamente ditas, estas só se tornam inteligíveis quando entram no aparelho psíquico através de representações. Enuncia-se uma tese, então, que não cansou de inquietar psicanalistas e comentadores: trata-se de um registro do somático no psíquico. Todavia, as coisas não permaneceram assim.

No artigo $O$ inconsciente, há uma sutil, mas importante diferença:

Uma pulsão não pode jamais se tornar objeto da consciência, apenas a ideia que a representa. Mas também no inconsciente ela não pode ser representada senão pela ideia. Se a pulsão não se prendesse a uma ideia ou não aparecesse como um estado afetivo, nada poderíamos saber sobre ela ${ }^{32}$.

Capturemos a questão: agora, a pulsão é algo não psíquico, de natureza somática que, através de um misterioso processo, adquire um representante no domínio psicológico. Pulsão e representante psíquico, tal como os termos são organizados nesse importante texto de metapsicologia, são duas coisas bem diferentes. Já James Strachey, nos comentários que faz a edição inglesa da obra de Freud, observara esses problemas. Independente das complicações, algo parece estar absolutamente fora de dúvida e é precisamente este ponto que mais nos interessa: trata-se sempre de pensar um processo nada simples de ser compreendido em que intensidades somáticas, aportes energéticos, elementos que vocacionam à descarga encontram expressão no campo do psicológico, adquirem tessitura representativa e, assim, podem ser conhecidos e estudadas como elementos que pressionam o aparelho psíquico. Há, assim, expressão no campo do psicológico de um elemento que demanda um constante esforço de trabalho por parte do aparelho, independente da forma como conceituamos a pulsão, pura potência somática ou representação psíquica dessas potências. $^{33}$

Não é por outra razão que Freud entenderá que se trata de um "conceito-limite entre o somático e o psíquico” ${ }^{34}$ e, o mais importante, a pulsão seria vista como “medida de trabalho imposto à psique por sua ligação com o corpo" ${ }^{35}$. Trata-se da já

\footnotetext{
${ }^{32}$ FREUD, $O$ inconsciente, p. 114-115.

${ }^{33}$ Luiz Roberto Monzani comenta a este respeito: “Trata-se sempre de um processo que, de tempos em tempos, opera uma transformação das moções biológicas em moções psíquicas em que uma energia orgânica se transforma em energia psíquica. De que esse processo é extremamente obscuro e difícil de ser compreendido não resta a menor dúvida. Mas esta parece ter sido a maneira como Freud o concebia. De resto, ele nunca negou o caráter vago e confuso da teoria psicanalítica das pulsões” (Freud - o movimento de um pensamento, p. 261).

${ }^{34}$ FREUD, Os instintos e seus destinos, p. 57.

${ }^{35}$ FREUD, Os instintos e seus destinos, p. 57.
} 
amplamente conhecida ideia de que a ligação do corpo com a alma, em Freud, é vista sob a ótica da entrada de fatores quantitativos, energéticos ${ }^{36}$ que, adquirindo pregnância no campo do psicológico, acionam circuitos de defesa e de processos altamente complexos que serão responsáveis, não só pelo desenvolvimento deste aparelho como pelas etiologias dos adoecimentos psicológicos ${ }^{37}$. Essa é precisamente uma das razões pelas quais se possa considerar a sexualidade, nesse momento, como profundamente perturbadora dos processos de equilíbrio do organismo e do aparelho psíquico - precisamente porque, à diferença importante com os outros estímulos fisiológicos, a pulsão sexual que pressiona o aparelho psicológico e que exige dele trabalho é entendida como um estímulo ininterrupto, como algo que não atua "jamais como força momentânea de impacto, mas sempre como força constante" ${ }^{38}$. A sexualidade pulsional freudiana é inerentemente motor de perturbações do psiquismo exigindo dele recursos cada vez mais sofisticados para que seja possível direcionar, canalizar, reprimir, sublimar, em suma, para que seja possível (lembrando da importância dos fatores culturais e sociais nesse processo) conter essa incessante atividade somático-psicológico e transformá-la, na medida do possível, em alguma coisa psiquicamente "organizada".

É partindo desse ponto que julgamos ser necessário associar a pulsão sexual como essencialmente vinculada à disrupção e a conflituosidade que, ademais, serão conceitos centrais até o fim do percurso freudiano. É daqui, igualmente, que se torna inteligível, a despeito da enorme complexidade desses processos, as sucessivas fases da sexualidade humana com suas cargas de deslocamentos e de repressões que farão com que a sexualidade adulta, "terminada", seja um constructo sempre mais ou menos estabelecido de um imenso caminho de desenvolvimento que tem em seus trilhos processos de fixações, regressões, represamentos, sublimações, formações reativas, etc. Assim, se uma das tarefas do aparelho psíquico, desde os primeiros momentos de sua atividade, lidando ainda com estímulos que o pequeno corpo infantil não pode senão sentir como profundamente selvagens e sem trégua, é precisamente "dominar

\footnotetext{
${ }^{36}$ Como será destacado prioritariamente após a introdução do Id e que conduzirá à elevação de ênfase dos fatores econômicos nos últimos textos de Freud. A este respeito, uma interessante discussão é proposta por MONZANI, L. R. Freud: o movimento de um pensamento. Campinas: Editora da Unicamp, 2014. Sobre a ênfase nos aspectos biológicos, a elevação da importância dos fatores energéticos no pensamento freudiano, uma boa leitura é GREEN, A. La concepción psicoanalítica del afecto. Buenos Aires: Siglo Veintiuno, 1975.

${ }^{37}$ Sobre as relações entre a perspectiva psicanalítica freudiana das pulsões com os tipos de adoecimentos psíquicos em sua obra, bem como para uma interessantíssima interpretação acerca das matrizes epistemológicas e clínicas e dos respectivos adoecimentos psíquicos a elas relacionados em diversos autores e escolas da psicanálise, Cf. FIGUEIREDO, L. C.; COELHO JUNIOR, N. E. Adoecimentos psíquicos e estratégias de cura: matrizes e modelos em psicanálise. São Paulo: Blucher, 2018.

${ }^{38}$ FREUD, Os instintos e seus destinos, p. 54.
} 
os estímulos" 39 da melhor maneira que puder, é impossível não extrairmos disso uma das descobertas mais importantes de Freud: há algo de inquietante e de perturbador na pulsão sexual (em todos os níveis metapsicológico) que faz com que ela seja, sempre e de alguma forma, fator de conflito, de exigência e de insaciedade.

E aqui retomaremos a nossa problemática central: toda a elaboração freudiana acerca da sexualidade humana, todas as suas lentas e profundas desconstruções e rupturas em relação à sexologia do XIX (e da nossa, talvez) evidenciando que a pulsão sexual e seu objeto não são pré-determinados, que a sexualidade infantil é profundamente anárquica movendo-se, inicialmente, numa superfície erógena que se apresenta em sua totalidade como capaz de secretar a sexualidade, que as perversões são constitutivas da sexualidade na medida em que reside aí uma característica universal do percurso sexual humano através de seus estágios primevos (e, posteriores); em suma, a ruptura freudiana acerca da sexualidade caminhou em direção à remoção deste conceito dos manuais de biologia para inseri-la, concomitantemente, no discurso psicanalítico onde ela se figura como inerentemente outra coisa que não apenas tendência à reprodução, vinculada a objetos naturalmente dados - tudo isso silenciar-se-á para que apenas Thânatos fosse considerado o grande elemento de perturbação?

Tendo todo esse laborioso trabalho de Freud em mente, qual não poderia ser a surpresa se, lendo as teses de 1920, a sexualidade humana tivesse se tornado fator de ligação, integração, construção de unidades e, desse modo, perdesse os seus mais distintivos elementos pacientemente elaborados nos anos anteriores. Se é preciso supor, como vimos, que a libido está subsumida a Eros e que, este, como igualmente acompanhamos, deseja a construção de unidades para retornar à unidade primordial, então a sexualidade humana, como sugerem alguns autores que acompanhamos, deixou o campo do conflito, da disrupção, da incessante perturbação para se afigurar como motor da união com os objetos na tendência de criar unidades.

Ocorre que não estamos completamente convencidos dessa posição. Se a ideia de que Eros seja conservador e que, por isso, deseje aglutinar, unir, ligar em busca de sua unidade perdida parece ser uma posição razoável na teoria freudiana, parece-nos ser, igualmente defensável, que a sexualidade se mantém solidamente construída sobre as mesmas bases argumentativas que foram elaboradas em toda metapsicologia. Isso já pressupõe, de saída, que a ideia de que haja rupturas definitivas em Freud, grandes movimentos de superação de teorias e que a obra caminharia rumo a sua maturidade eliminando temas e aspectos de suas fases precedentes, não nos parece ser justificada. Há uma única obra freudiana, acreditamos, complexamente construída de

\footnotetext{
${ }^{39}$ FREUD, Os instintos e seus destinos, p. 55.
} 
deslizamentos e retomadas que, a despeito das contradições e dificuldades, articula-se num todo sistematicamente organizado.

Eros pode agregar, sedento deus devorador de individualidades na sua marcha para ligar. Mas isso não significa, de modo algum, que a sexualidade tenha passado para o lado da harmonia. E por que não?

\section{Libido e indivíduo: a sexualidade reencontrada.}

Como não poderia ser diferente, dos mesmos textos em que vimos a constante vacilação por parte de Freud acerca da ideia da conservação, extrairemos agora os argumentos que parecem confirmar que a sexualidade mantém seu estatuto disruptivo no pensamento freudiano após a introdução de Eros. No já citado Compêndio de psicanálise, encontraremos o seguinte:

Denominamos pulsões as forças que supomos existir por detrás das tensões motivadas pelas necessidades do Isso. Elas representam as exigências corporais feitas à vida anímica. Ainda que sejam de natureza conservadora; de cada estado que um ser alcançou resulta um esforço para restabelecê-lo, tão logo ele tenha sido abandonado ${ }^{40}$.

Trata-se de um texto muito posterior, como é evidente, as profundas transformações ocorridas em Além do princípio do prazer e, inclusive, fica bastante claro como Freud refere-se à temática que traçamos anteriormente, a famigerada “natureza conservadora das pulsões". Mas, qual não é a nossa surpresa, então, quando percebemos que, mesmo retomando as complicadas questões acerca da natureza das pulsões, Freud as pensa, mutatis mutandis, da mesma forma como havia caracterizado a pulsão em 1915, isto é, “como uma exigência corporal feita à psique”. O psiquismo, então, é constantemente atingido por forças e demandas que exigem que sejam mobilizados recursos e formas de controle da situação.

Desse ponto de vista e ao contrário do que as especulações elaboradas em 1920 poderiam sugerir à primeira vista, a libido (subsumida a Eros) continua sendo encarada como elemento que eleva tensões, exige trabalhos, busca descargas e, no limite, é uma atividade profundamente perturbadora à dinâmica psíquica. Ainda no Compêndio de psicanálise, encontraremos:

O cerne do nosso ser é, portanto, formado pelo obscuro Isso, que não lida diretamente com o mundo exterior e só é acessível, mesmo ao nosso conhecimento, pela mediação de outra instância. No Isso operam

\footnotetext{
${ }^{40}$ FREUD, Compêndio de psicanálise, p. 23.
} 
as pulsões orgânicas, sendo elas mesmas uma mistura de duas forças primevas (Eros e destruição) [...] o único anseio das pulsões é a satisfação, a qual se espera surgir de determinadas modificações nos órgãos com auxílio de objetos do mundo externo. Mas uma satisfação imediata e desconsiderada das pulsões, tal como o Isso exige, levaria com frequência a perigosos conflitos com o mundo exterior e à ruína ${ }^{41}$.

As coisas estão claras: pulsões desejam descarga, seu único anseio é a satisfação, a atividade pulsional é de tal ordem disruptiva que pode, inclusive, ameaçar a integridade do próprio organismo. Ao que tudo indica, Freud está recuperando, ao mesmo tempo em que retoma as polêmicas teses de 1920, as elaboraçôes acerca da especificidade das pulsões que estão afiguradas nos textos de metapsicologia e em outros do mesmo período (como em Formulaçôes sobre os dois princípios de funcionamento psíquico, por exemplo). Isso pode ser sintetizado, a este respeito, da seguinte forma: caso fossem permitidas às pulsões livre escoamento, possiblidade de descarga sem ponderações e bloqueios, a própria subjetividade seria aniquilada.

Ora, não estamos precisamente no mesmo texto que, após 1920, trabalha com as ideias extraídas do segundo dualismo pulsional (em que, portanto, a libido já se tornou uma parte de Eros) e, ainda assim, mantém rigorosamente em pé a tese de que as pulsões são fator de perturbabilidade ocasionam profundas situações de conflito e de intensidade? Não se trata, mais uma vez, de deixar estabelecido que, enquanto exigência de trabalho à psique, a pulsão mantém seu caráter intensivo e energético como motor de perturbações? Não se trata, em suma, de questionar a ideia de que pelo fato das construções sobre Eros levarem Freud a incluir a libido sobre seus domínios, não estarmos autorizados a concluir disso que a sexualidade se tornou o contrário daquilo que sempre fora em suas teorizações? Daí nossa dificuldade de imaginar que a sexualidade, quando pensada pelo registro de Eros, torna-se, de repente, pura positividade.

Não é por outra razão que acreditamos que, mesmo nas profundas dificuldades que derivam da ideia de conservação e tendência à unidade aplicados a Eros, Freud pode elencar, sem complicações, em textos como Compêndio de psicanálise e nas Novas conferencias introdutórias à psicanálise, as fases da sexualidade e evidenciar as transformações da libido de modo muito semelhante ao feito em 1905, uma vez que a libido, a sexualidade, não perdeu seu caráter de negatividade e nem de exigir do aparelho psíquico uma constante tarefa energética, dinâmica e social de transformação, contenção, e redirecionamento das pulsões sexuais.

O primeiro órgão que se apresenta como zona erógena e coloca, a partir do nascimento, uma exigência libidinal ao psiquismo é a boca.

${ }^{41}$ FREUD, Compêndio de psicanálise, p. 155. 
Inicialmente, toda atividade psíquica se prepara para trazer satisfação às necessidades dessa zona. Ela serve naturalmente, em primeiro lugar, à autoconservação através da alimentação, no entanto, não se pode confundir Fisiologias com Psicologia ${ }^{42}$.

A organização completa só é alcançada através da puberdade em uma quarta fase, a genital. Então se estabelece um estado no qual 1) Algumas cargas libidinais da primeira infância permanecem retidas; 2) outras são incorporadas na função sexual como ações preparatórias, auxiliares, cuja satisfação produz o assim chamado prazer preliminar; 3) outros anseios excluídos da organização são ou absolutamente reprimidos ( recalcados) ou experimentam outra aplicação no Eu: configuram traços de caráter e sofrem sublimações como o deslocamento da meta ${ }^{43}$.

E, aqui, podemos retomar uma ideia que deixamos em suspensão. Parece-nos fundamental atentar-se ao final do segundo capítulo do Compêndio de psicanálise, onde se afirma que "na opinião popular vigente" 44 , libido e Eros correspondem inteiramente, mas na psicanálise essa identidade não é suposta. Esse ponto não pode ser subestimado sob risco de perdermos algo de profundamente importante: ainda que Eros esteja intimamente associado a ideia de ligação e construção de unidades cada vez maiores, ainda que a sexualidade possa compartilhar dessas funções, isso não nos autoriza imaginar que a sexualidade perdeu seus traços distintivos já construídos por Freud, pois Eros engloba a libido, mas, como é evidente, não a transforma por isso em algo completamente agregador. Tomar a sexualidade, no segundo dualismo, como signo da ligação e da união de partes sem estar atento as turbulentas redes que a libido pode ocasionar é homogeneizar um processo que, ao nosso ver, Freud não endossa. A desorganização causada pela vida pulsional mantém-se um argumento central para que a conflituosidade e a incessante e perturbadora atividade dos desejos sejam compreendidas:

O próprio Isso é uma fonte de perigos semelhantes, e isso por dois motivos distintos. Em primeiro lugar forças pulsionais excessivas podem prejudicar o Eu de modo semelhante aos "estímulos" excessivos do mundo exterior. É verdade que não podem aniquilá-lo, mas podem destruir sua organização dinâmica e transformar o Eu, novamente, numa parte do $\mathrm{Isso}^{45}$.

\footnotetext{
${ }^{42}$ FREUD, Compêndio de psicanálise, p. 37.

${ }^{43}$ FREUD, Compêndio de psicanálise, p. 41.

${ }^{44}$ FREUD, Compêndio de psicanálise, p.31.

${ }^{45}$ FREUD, Compêndio de psicanálise, p. 159.
} 
Esse importante excerto nos dará oportunidade de propormos uma última distinção que nos parece necessária e organizarmos as peças que mobilizamos até aqui. Muitas das especulações mais profícuas acerca de Eros serão encontradas em $O$ mal-estar na civilização, onde Freud afirmará que "Eros e Ananke tornaram-se também os pais da cultura humana” ${ }^{46}$. Não é nosso propósito, por motivos evidentes, adentrar as análises culturais de Freud, mas destacaremos algo fundamental: ali se evidencia que, devido a tendência de unir, ligar, produzir agregação e vincular individualidades (em que tudo se inicia, desdobrando as teses de Totem e tabu, com a família primitiva que será o conjunto dos primeiros colaboradores no trabalho), Eros deve ser peça central da formação da cultura. Esta, sendo um "processo especial que se desenrola na humanidade" ${ }^{47}$ não poderá estar submetida a outra coisa senão "a serviço de Eros, que pretende juntar indivíduos numa grande unidade, a da humanidade" ${ }^{48}$.

Aqui Freud destaca, então, o essencial: a compreensão do processo cultural é vê-lo associado a Eros pois, como vimos, este possibilita um movimento em que a formação social da comunidade (e da humanidade) se dá em sua processualidade libidinal através da união com os outros, cumprindo aí o desejo de restaurar a unidade perdida. A questão, contudo, é que não podemos deduzir desse processo cultural as mesmas conclusões e resultados quando se trata do nível individual das manifestações de Eros, pois os processos da sexualidade não poderão conduzir aos mesmos resultados, precisamente porque, ao homogeneizar esses dois níveis, perdemos algumas especificidades centrais. E elas repousam precisamente na compreensão de que, se Eros quer conservar e criar unidades, ligar, do ponto de vista do indivíduo, palco de onde brota a atividade pulsional, esse processo é acompanhado das mais violentas e disruptivas demandas pulsionais. Vejamos isso.

A teorização de Freud sobre o cultural trabalha sobre um pressuposto central, a ideia de que entre indivíduo e cultura a diferença dos processos reside apenas no grau de suas manifestações ${ }^{49}$. Esta polêmica tese, que gerou acusações de psicologismos por parte

\footnotetext{
${ }^{46}$ FREUD, O mal-estar na civilização, p. 63.

${ }^{47}$ FREUD, O mal-estar na civilização, p. 90.

${ }^{48}$ FREUD, $O$ mal-estar na civilização, p. 90.

${ }^{49}$ Renato Mezan, no Brasil, dedica-se a pensar essa questão, entre inúmeras outras, no seu Freud: pensador da Cultura. Acerca dessa homogeneidade entre social e individual, o autor explicita: "Se é certo que ninguém vive à margem da cultura a que pertence - mesmo o delírio psicótico toma elementos da religião e dos acontecimentos circundantes, e já a língua em que se exprime o delirante lhe é fornecida pela civilização de referência - , também é verdade que entre o mundo interior de cada pessoa e o campo do social-histórico se abre um abismo, que não pode ser transposto pela mera constatação de que certos fenômenos se verificam num e noutro plano. Diante dessa diferença que se impõe entre o indivíduo e o social-histórico, Freud optará por um caminho [...]: o de supor que entre o indivíduo e o social vige uma analogia, e que tal analogia é ampla e fundada o suficiente para permitir a transposição de categorias forjadas no primeiro para elucidar
} 
de Freud, de perder de vista o estatuto próprio ao social, é construída sempre sobre a referência dos processos da psique individual. Sabemos que essa orientação metodológica (que, eliminada a superficialidade, parece ser mais complexa do que se julga inicialmente) está presente cabalmente na ideia de que entre o desenvolvimento individual da libido e as fases pelas quais a "evolução" da civilização passou há uma homogeneidade estruturante, o que faz com que Freud possa analisar, por exemplo, os estágio do animismo dos primitivos como o momento de narcisismo do desenvolvimento infantil (via onipotência dos pensamentos), assim como as formas de religião como associadas à figuração edípica, onde as figuras paternas e maternas são centrais a estruturação da subjetividade. Assim, no longo processo da cultura, com suas crises, regressões, destrutividades, repressões, transformações o que vemos é a artimanha de Eros agregando unidades, desviando pulsões de morte de uns contra os outros, e fortalecendo ligações libidinais inibidas em meta. Desse ponto de vista, assim como no indivíduo as sucessivas e complexas fases de maturação sexual conduzem às repressões necessárias, aos fortalecimentos das tendências sociais e a instauração do princípio de realidade, também na longa marcha da cultura o que vemos são os conflitos das pulsões sem que se anule a tarefa agregadora de Eros, pois o plano da cultura é uma das mais observáveis manifestações das tendências à ligação que foram unidas às pulsões de vida em 1920.

Mas este argumento, freudiano por excelência, possui uma face fácil de ser perdida e que julgamos central. Vejamos essa passagem de $O$ mal-estar na civilização

No desenvolvimento individual [...] a ênfase cai geralmente na aspiração egoísta ou à felicidade. Outra, que pode ser chamada "cultural", contentase, via de regra, com o papel restritivo. É diferente no processo cultural. Nele, o principal é, de longe, a meta de criar uma unidade a partir dos indivíduos humanos, a meta da felicidade ainda existe, mas é impelida para segundo plano; quase parece que a criação de uma grande comunidade humana teria êxito maior se não fosse preciso preocupar-se com a felicidade do indivíduo ${ }^{50}$.

Focalizemos a importância dessa passagem: Eros certamente está presente no indivíduo e na cultura, mas isso não significa que os mesmos efeitos sejam assistidos quando se trata de sua manifestação nesses dois domínios. Do ponto de vista da cultura, a

\footnotetext{
processos ocorrentes nos segundo”(p. 482). E o mesmo autor provoca: “[...] por que, com efeito, seriam dotados de uma afinidade substancial o psíquico e o social? E se, ao contrário, fossem ambos irredutíveis, e o projeto de uma teoria unificada do humano, capaz de explicar todos os fenômenos nos dois campos, fosse apenas um fantasma, ele sim redutível à onipotência do pensamento, sempre em vigor no inconsciente?” (MEZAN, Freud: pensador da cultura p. 391).
} ${ }^{50}$ FREUD, O mal-estar na civilização, p. 115. 
agregação, a conservação das unidades está ao lado da tentativa de criar laços, harmonias, reencontro da unidade. Mas em cada indivíduo que compõe a cultura, o processo se dá de modo diferente, pois do seu ponto de vista, de suas aspirações pulsionais "egoístas”, o que se desenha é a perturbação do aparelho psíquico, é o conflito inerente da pulsão contra as repressões sociais, é o sentimento de culpa gerado pela insistência do desejo e pela onipresença da censura, é o velha e conhecida "exigência de trabalho à psique”. Isto é, "o processo de desenvolvimento individual pode ter traços especiais, que não se repetem no processo cultural humano [... $]^{51}$ " precisamente porque, no sujeito individual, a meta de unificação e agregação estará sempre acompanhada de conflito, disrupção, tensões ininterruptas, embates com a alteridade e com a estrutura narcísica do Eu. Tudo se passa como se Eros, em sua ininterrupta marcha, sendo uma das pulsões primordiais que a tudo engloba para reencontrar a unidade perdida, causasse, no nível do sujeito, as mais violentas marcas e a intensa necessidade de que o sujeito lide com esses atravessamentos pulsionais. Parece ser por isso que Freud compreende que a luta entre indivíduo e sociedade não repousa apenas na agressividade de cada um de nós, mas significa "uma desavença na casa da libido, comparável à briga pela distribuição da libido entre Eu e os objetos [...]" ${ }^{52}$. Bem pode ser que Eros agregue e faça de cada indivíduo um personagem no longo processo de unificações e agregações, mas isso acarreta uma situação economicamente conturbada para o desenvolvimento de cada um de nós ${ }^{53}$.

Então, organizemos as coisas mobilizando os argumentos que Freud parece construir quando se trata de compreender as pulsões no segundo dualismo pulsional: ambas são conversadoras, ainda que desejem conservar coisas diferentes, ambas são movimentos incessantes que exigem coisas radicalmente distintas - uma deseja a morte, anular excitações, a outra deseja a unidade e, introduzindo tensões e exigindo movimentos para englobar a alteridade e reencontrar sua unidade, exige do aparelho mental um trabalho constante. Tudo isso é verdadeiro, mas é preciso ter claro que, ainda que a libido possa compartilhar com Eros seus aspectos agregadores, isso não significa que, no plano

\footnotetext{
${ }^{51}$ FREUD, O mal-estar na civilização, p. 115.

52 FREUD, O mal-estar na civilização, p. 116.

${ }^{53}$ E será precisamente das teses de Além do princípio do prazer que Freud não cessará de ampliar suas especulações da teoria pulsional para abarcar, dos níveis moleculares da substância orgânica até os conflitos culturais entre nações. O que subjaz como elemento de inteligibilidade é justamente a lógica da luta pulsional entre Eros e Thânatos. As duas pulsões fundamentais atravessariam, desse modo, as grades subjetivas dos fenômenos psíquicos e orgânicos, para serem móveis de explicação genuinamente psicanalítica de camadas políticas, históricas, religiosas, na luta entre grupos e na guerra entre nações. Mas, se por um lado esse resvalar numa metafísica geral (na nossa leitura, contudo, por mais próximo que a metapsicologia possa ser de algumas tradições da metafísica ocidental, a especificidade da psicanálise resguarda sua identidade e não nos parece facilmente defensável vinculá-la sem mais à filosofia) se anuncia em algumas passagens de Freud (como, por exemplo, na proximidade assumida por Freud de suas teses com a cosmologia filosófica de Empédocles) não se pode disso concluir que os níveis de manifestação das pulsões são homogêneos — de fato, se se trabalha na ideia de que entre social e individual não há diferenças de natureza, isso não permite concluir que os princípios que atuam nessa totalidade se manifestem de modo igual em cada nível analisado, pois a homogeneidade da presença dos princípios não dilui diferenças nos planos de manifestação, cultural e individual, por exemplo.
} 
do indivíduo, na sua história subjetiva e nos processos que the são internos, as tensões constantemente introduzidas e que são desejosas da unidade, não deixem um rastro de violentas marcas excitatórias que por diversos caminhos deverão ser represadas, deslocadas e transformadas na longa e tortuosa história de desenvolvimento do sujeito. Isso significa que a sexualidade freudiana não perdeu seus elementos constitutivos após a introdução de Eros, na medida em que, em cada novo sujeito e em cada novo processo de subjetivação, continuam firmemente atuantes as exigências de trabalho à psique, as demandas pulsionais selvagens e vocacionado descarregar suas tensões. Eros pode desejar a unidade, mas os processos através dos quais sua tendência se manifesta, são sempre, para o sujeito, fatores de perturbações.

Por isso, se à primeira vista, tudo parece indicar que Eros e libido tornaram-se plenas positividades e são responsáveis apenas pelos processos de integração das tessituras psíquicas, é preciso não perder de vista que:

[...] somos levados a impressão de que as pulsões de morte são mudas essencialmente, e de que o fragor da vida parte de Eros. E da luta contra Eros! É difícil não imaginar que o princípio do prazer serve ao Id como uma bússola no combate à libido, que introduz perturbações no curso da vida ${ }^{54}$.

Eros e pulsão de morte lutam dentro dele, vimos com que meios uma dessas classes de pulsões se defende da outra. Poderíamos imaginar que o Id se acha sob dominação das silenciosas, mas poderosas, pulsões de morte, que querem ter paz e fazer calar Eros, o estraga sossegos, por instigação do princípio do prazer; mas com isso tememos subestimar o papel de $\operatorname{Eros}^{55}$.

Em nenhum momento, no interior da obra de Freud, assumiu-se que os fatores de conflituosidade que tanto colorem sua psicologia seriam derivados apenas da luta entre Eros e Thânatos, e apenas do conflito entre pulsões de autoconservação e sexuais, no segundo e primeiro dualismo pulsionais, respectivamente. Parece-nos que a proposta de Freud é mais radical: há algo de indomável na natureza mesma da pulsão, estando elas a serviço da conservação ou não, desejosas de unir e agregar ou destruir e desligar, sedentas por reencontrar o seu "outro si-mesmo" ou para aniquilar qualquer nova tensão, em suma - expandindo, repetindo ou conservando estamos diante de um conceito-limite que introduz, sempre, na experiência da subjetividade humana elementos de constante mobilizações. É evidente que nunca devemos perder de vista o embate entre pulsões de vida e pulsões de morte, fusões e defusões pulsionais que colorem a totalidade dos processos psicológicos (e biológicos, a julgar

\footnotetext{
${ }^{54}$ FREUD, $O$ eu e $o$ id, p. 58, grifo nosso.

${ }^{55}$ FREUD, $O$ eu e $o$ id, p. 74.
} 
por Além do princípio do prazer). Atentamo-nos, nesse pequeno percurso, para o interior do próprio Eros que não precisa de Thânatos para ser fator de conflito.

A este respeito, podemos inclusive recuperar aspectos importantes de nossa discussão e compreendê-los melhor. A oposição que fora estabelecida entre expansão e conservação pode ser mais bem trabalhada se pensarmos nessas duas faces de Eros: um agregador e sedento por unidades e outro Eros ${ }^{56}$ fator de tensão, violenta disrupção, incessante "quantum" de trabalho. Desse ponto de vista, o que Freud faz não é perder esses conceitos em ambiguidades insolúveis, mas sofisticar a forma de compreendê-los, pois expandir não se opõe à conservação, assim como agregar, unir, ligar, não se oporá à conflituosidade. No plano filogenético, a longa marcha de Eros agrega e faz o que for possível para manter unidades, ele expande visando recuperar o "si-mesmo perdido" e deseja conservar as unidades conquistadas, mas no plano ontogenético, esse trabalho é sempre sentido dentro das limitadas capacidades de controle, de elaboração, de simbolização, de ordenamento próprios ao indivíduo. A cada novo sujeito humano que chega à vida, inclusive relembrado da prematuracão estruturante da criatura humana, a marcha "erótica” se presentifica mais uma vez e, mais uma vez, ela é central tanto para o desenvolvimento do aparelho psíquico, quanto é motor de suas perturbações. Na verdade, é porque o sujeito é desde o início atravessado por demandas que não pode controlar sozinho, que não pode satisfazer sem o auxílio do mundo, que haverá a gradativa passagem do processo primário para o secundário. É a frustração de não ser capaz de eliminar suas próprias tensões que promoverá o desenvolvimento de importantes funções do aparelho psíquico, como a lenta consideração pelo mundo exterior. Freud, então, articula esses conceitos de tal modo, complexo, sem dúvida, que expansão não se oporá à conservação, bem como repetir é uma forma de, gerando tensões, produzir o movimento, a transformação, a diferença. Assim, a sexualidade subsumida a Eros continua sendo força indomável e exige esforços incontornáveis do aparelho anímico.

\section{O incapturável do Além do princípio do prazer.}

Talvez resida nesse ponto da psicanálise freudiana uma das mais importantes questões para se pensar a nossa tão anunciada liberdade sexual no mundo contemporâneo. Nossa anunciada dissolução dos aparelhos repressores vitorianos que teriam sido a contextura social própria às produções de Freud e que, superadas, não nos diriam mais respeito: tratar-se-ia, agora, da possiblidade de fruir do próprio corpo, da vivência da sexualidade humana em suas potencialidades mais desejadas por épocas anteriores; finalmente, assistiríamos a gradativa destruição das repressões e

\footnotetext{
${ }^{56}$ Reiteramos, é claro, que se trata de um único Eros. O texto freudiano não permite pensar várias "Eros” ou vários “Thânatos". Insistimos nas diferenças dos efeitos nos níveis da manifestação das pulsões de vida, aspectos distintos completamente redutíveis as tendências gerais de Eros.
} 
tabus que eram impostos por um mundo no qual viver a tão complexa sexualidade era fator de polícia e não de psicanálise.

Mas, a se levar em consideração nossa discussão, há algo de misteriosamente estranho nas nossas formas atuais de viver a tão anunciada sexualidade. E talvez o fator de inquietação repouse na profunda positividade que ela parece assumir toda vez que, ao lado de sua irrupção e de suas várias faces, o sujeito se veja completamente identificado, colado às manifestações pulsionais de seu próprio corpo e psique. Como se, de um ponto de vista genuinamente freudiano, se pudesse domar, capturar, integrar completamente essa força que nos exige trabalho, demanda esforço de simbolização que, no limite, nunca poderá esgotar as constantes exigências que nos atravessam. Há algo de inerentemente perturbador na ligação mente e corpo, algo que nos espanta profundamente não porque a sexualidade infantil, que Freud nos descreveu, seja esse caldeirão polimorfo de tendências anárquicas e perversas, incompreendidas pela jovem psique infantil, mas porque a nossa sexualidade, adulta e “acabada”, “unitária”, "estruturada”, permanece sempre incomodamente infantil, sempre deslocada, sempre outra coisa que apenas seus objetos artificialmente acoplados. Sempre evidenciando os limites de nossa atuação racional sobre essas intensas experiências de atravessamento.

Talvez a verdadeira inquietação do Eros freudiano, em sua expansão, repetição e conservação, seja uma das razões pela qual é tão longeva a experiência de se ler Além do princípio do prazer, mesmo cem anos depois de sua publicação. Ali Freud é vacilante, hesitante, avança e recua tentando capturar algo que é, afinal, de natureza pulsional: conhecemos pelos seus efeitos e, de alguma forma, está sempre a nos perturbar do interior mesmo de sua misteriosa natureza e de sua imperiosa exigência sobre todos nós.

\section{Referências}

DELEUZE, G. Diferença e repetição. São Paulo, Editora: Paz \& Terra, 2018.

FIGUEIREDO, L. C.; COELHO JUNIOR, N. E. Adoecimentos psíquicos e estratégias de cura: matrizes e modelos em psicanálise. São Paulo: Blucher, 2018.

FREUD, S. Além do princípio do prazer. Tradução de Paulo César de Souza. São Paulo: Companhia das Letras, 2010.

FREUD, S. Compêndio de psicanálise. Tradução de Pedro Heliodoro Tavares. Belo Horizonte: Autêntica, 2019.

FREUD, S. Novas conferências introdutórias à psicanálise. Tradução de Paulo César de Souza. São Paulo: Companhia das Letras, 2010. 
FREUD, S. O eu e o id. Tradução de Paulo César de Souza. São Paulo: Companhia das Letras, 2011.

FREUD, S. O mal-estar na civilização. Tradução de Paulo César de Souza. São Paulo: Companhia das Letras, 2010.

FREUD, S. O inconsciente. Tradução de Paulo César de Souza. São Paulo: Companhia das Letras, 2010.

FREUD, S. Os instintos e seus destinos. Tradução de Paulo César de Souza. São Paulo: Companhia das Letras, 2010.

GREEN. A. A sexualidade tem algo a ver com a psicanálise? In: Livro anual da psicanálise, tomo XI. São Paulo: Escuta, 1995.

HOFFMANN, B. A Por uma psicanálise com sexualidade. In: SIG - Revista de psicanálise, n.1, vol. 2, p. 37 - 50, 2013.

LAPLANCHE, J.; PONATLIS, B. Diccionario de psicoanálisis. Buenos Aires: Paidós, 2004.

LAPLANCHE, J. Freud e a sexualidade: o desvio biologizante. Rio de Janeiro: Jorge Zahar, 1997.

MEZAN R. Freud: pensador da cultura. São Paulo: Blucher, 2019.

MONZANI, L. R. Freud - o movimento de um pensamento. Campinas: Editora Unicamp, 2014.

RAULET, G. As duas faces da morte. Sobre o estatuto da agressividade e da pulsão de morte em “O mal-estar na civilização”. In: Rider, J.; Plon, M.; Raulet, G.; Rey-Fleu. Em torno do mal-estar na cultura, de Freud. Tradução de Carmen Lucia Montechi Valladares de Oliveira. São Paulo: Escuta, 2002. 